\title{
PENGARUH BAURAN RITEL TERHADAP KEPUTUSAN PEMBELIAN KONSUMEN PADA DEPARTEMEN STORE X DI DKI JAKARTA
}

\author{
Freddy Simbolon \\ Jurusan Manajemen, Fakultas Ekonomi dan Bisnis, Bina Nusantara University \\ Jln. KH Syahdan No 9, Kemanggisan, Palmerah, Jakarta Barat 11480
}

\begin{abstract}
This study aims to measure how much influence the retail mix to the purchasing decision. To measure, the study used 100 respondents to the Department Store buyer X. The analytical method used is multiple regression method. Based on the analysis results obtained under the seven aspects of the retail mix of Merchandising, Price, Location, Promotion, Store Design \& Visual Product, Service, and Personnel, only two qualities that give them significant influence on consumer purchasing decisions of Price and Personnel. However, based on ANOVA, the overall of the seven aspects significantly influence consumer purchase decisions.
\end{abstract}

Keywords: retail mix, purchasing decision, department store

\begin{abstract}
ABSTRAK
Penelitian ini bertujuan untuk mengukur seberapa besar pengaruh dari bauran retail terhadap keputusan pembelian. Untuk mengukur tersebut, penelitian menggunakan 100 responden pembeli pada Departemen Store X. Adapun metoda analisis yang digunakan adalah metoda regresi berganda. Berdasarkan hasil analisis didapatkan bawah dari tujuh aspek bauran retail yaitu Merchandising, Price, Location, Promotion, Store Design \& Visual Product, Service, dan Personel, hanya dua aspek saja yang memberikan pengaruh secara signifikan terhadap keputusan pembelian konsumen yaitu Price dan Personel. Namun berdasarkan uji ANOVA, secara keseluruhan dari ketujuh aspek tersebut berpengaruh secara signifikan terhadap keputusan pembelian konsumen.
\end{abstract}

Kata kunci: bauran retail, keputusan pembelian, departemen store 


\section{PENDAHULUAN}

Seiring dengan perkembangan sosial ekonomi masyarakat, gaya hidup masyarakat di lingkungan Jakarta telah bergeser dalam melakukan transaksi pembelanjaan. Seperti yang dikemukakan oleh Khoiri (2011), saat ini pusat perbelanjaan di Jakarta tidak lagi sekedar menjadi tempat transaksi ekonomi, namun telah menjadi sebuah jantung kehidupan bagi masyarakat urban. Hampir di setiap sudut mal-mal yang ada di Jakarta telah dihiasi oleh berbagai gerai-gerai mewah, barang-barang konsumsi gaya hidup, dan tempat berkumpulnya masyarakat sebagai pusat kegiatan sehari-hari masyarakat perkotaan.

Meningkatnya perilaku masyarakat dalam melakukan transaksi ekonomi tersebut telah berdampak kepada perkembangan industri retail dengan konsep mega retail seperti Mall of Indonesia yang memiliki konsep retail termegah yang dikelola secara modern dan terintegrasi dengan berbagai unit layanan lainnya seperti perkantoran, apartemen, hiburan (entertainment) dan pusat jajanan. Konsep mega retail yang dikembangan tersebut telah menjadi pesaing bagi retail yang hanya berdiri sendiri dan tidak terintegrasi dengan pusat-pusat layanan lainnya. Perkembangan mega retail modern lebih banyak terfokus di DKI Jakarta yang mempengaruhi perilaku masyarakat perkotaan untuk berbelanja pada konsep mega retail. Menurut perkiraan Business Intelligence Report (BIRO), pertumbuhan gerai ini, khususnya asing, akan semakin pesat, dan hingga 2008 akan mencapai sekitar $8 \%$ dan akan menguasai lebih dari $25 \%$ dari total omzet retail nasional.

Penelitian ini dilakukan pada departemen store X yang merupakan salah satu retail modern sebagai tempat belanja pilihan bagi masyarakat di DKI Jakarta. Sebagai salah satu departemen store, perusahaan ini memposisikan diri sebagai pusat perbelanjaan bagi golongan menengah atas. Apalagi saat ini lokasi yang dipilih pun berada pada kawasan yang strategis dengan komunitas masyarakat menengah atas. Walaupun dengan semakin gencarnya pertumbuhan pusat perbelanjaan dengan konsep mega retail, maka akan menjadi tantangan bagi departemen store ini untuk mengemas bauran pemasaran retail agar tidak kalah dalam persaingan dengan pusat perbelanjaan yang menggunakan konsep mega retail.

Penelitian ini dilakukan untuk mengukur pengaruh bauran retail terhadap pengambilan keputusan pembelian pada departemen store X di DKI Jakarta. Dipilihnya lokasi ini karena perusahaan ini memiliki karateristik tersendiri dalam pengelolaanya, yaitu perusahaan retail bagi golongan menengah atas dan dikelola oleh perusahaan nasional. Adapun rumusan masalah yang akan dijawab pada penelitian ini adalah bagaimana pengaruh bauran retail terhadap pengambilan keputusan pembelian pada perusahaan retail modern? Atas dasar rumusan masalah tersebut, maka tujuan yang akan dicapai pada penelitian ini adalah untuk mengetahui pengaruh penerapan bauran retail terhadap pengambilan keputusan pembelian pada perusahaan retail modern. Penelitian ini diharapkan dapat menjadi masukan bagi perusahaan retail modern lainnya dalam memahami konsep manajemen retail modern dan pengaruhnya terhadap pengambilan keputusan pembelian masyarakat di DKI Jakarta.

\section{Tinjauan Pustaka}

\section{Bauran Retail}

Konsep tentang bauran retail diungkapkan oleh Levy \& Weitz dalam Zulfikar (2008) bahwa bauran retail merupakan kombinasi dari faktor-faktor retail yang digunakan untuk memuaskan kebutuhan pelanggan sehingga dapat mempengaruhi keputusan pembelian. Adapun faktor-faktor tersebut adalah barang dagangan (merchandising), harga (price), promosi (promotion), rancangan toko dan pajangan produk (store design and display merchandise), lokasi (location), pelayanan (service), dan wiraniaga (personel). 
Literatur lainnya yaitu Davidson (1988) mengungkapkan bahwa bauran retail terdiri atas physical facilities and location, merchandising, pricing, promotion, service, organization and personnel. Namun pada penelitian ini untuk mengukur bauran retail digunakan konsep yang dikemukakan oleh Levy \& Weitz (dalam Zulfikar, 2008). Bauran retail memberikan pengaruh terhadap perilaku pengambilan keputusan konsumen, hal ini seperti yang telah disampaikan oleh Zulfikar (2008). Penelitian yang dilakukan pada Toserba X di Bandung memberikan hasil bahwa bauran retail dapat memberikan pengaruh kepada perilaku pengambilan keputusan pembelian dimana konsumen menjadi loyal terhadap toserba tersebut.

\section{Perilaku Keputusan Pembelian}

Perilaku konsumen merupakan sebuah tindakan-tindakan yang disebabkan oleh pengalaman seseorang terhadap produk, pelayanan dan sumber lainnya. Hal ini seperti yang dikemukakan oleh Zaltman \& Wallendrof yang dikutip oleh Mangkunegara (1988) mengatakan bahwa perilaku konsumen adalah tindakan-tindakan, proses, dan hubungan sosial yang dilakukan oleh individu, kelompok, dan organisasi dalam mendapatkan, menggunakan suatu produk atau lainnya sebagai suatu akibat dari pengalamannya dengan produk, pelayanan, dan sumber-sumber lainnya.

Selanjutnya perilaku konsumen menurut Sumarwan (2004) merupakan semua kegiatan, tindakan, dan proses psikologis yang mendorong tindakan tersebut pada saat sebelum membeli, ketika membeli, menggunakan, menghabiskan produk, dan jasa setelah melakukan hal tersebut atau kegiatan mengevaluasi.

Menurut Assael (1987) ada tiga faktor yang mempengaruhi pengambilan keputusan konsumen yaitu: (1) faktor individual konsumen yang meliputi pendidikan dan penghasilan konsumen; (2) pengaruh lingkungan; (3) strategi pemasaran. Strategi pemasaran merupakan variabel yang dapat dikontrol oleh pemasar dalam usaha memberi informasi dan mempengaruhi konsumen. Sehingga di dalam pengambilan keputusan konsumen terdapat dua faktor yang memberikan pengaruh yaitu individu dan faktor luar dalam hal ini adalah lingkungan dan perusahaan dalam menjalankan strategi pemasaran.

Selanjutnya menurut Schiffman \& Kanuk (2000), studi perilaku konsumen dalam pembelian menyangkut apa yang mereka beli, mengapa mereka membeli, kapan mereka membeli, di mana mereka membeli, seberapa sering mereka membeli, dan seberapa sering mereka menggunakannya. Selain itu, studi perilaku pembelian juga menyangkut evaluasi pasca pembelian produk yang mereka beli. Sehingga dengan mempelajari perilaku tersebut, Kotler \& Armstrong (1994) mengungkapkan bahwa karakteristik pembeli terdiri atas empat faktor utama, yaitu kultural, sosial, pribadi, dan psikologis. Keempat faktor tersebut akan mampu mendorong konsumen dalam berperilaku memilih produk dan jasa yang ditawarkan perusahaan.

Atas dasar pengertian-pengertian yang disampaikan di atas maka dapat disimpulkan bahwa perilaku konsumen dalam keputusan pembelian merupakan tindakan keputusan pembelian terhadap suatu produk dan jasa yang didasarkan oleh berbagai hal pada dirinya dan lingkungannya, termasuk di dalamnya adalah lingkungan kenyamanan berbelanja, saran orang lain, informasi-informasi yang disampaikan oleh perusahaan, seperti promosi, daya tarik keunggulan produk dan layanan sehingga akan berdampak kepada perilaku untuk merekomendasikan kepada orang lain.

\section{Pengaruh Bauran Retail terhadap Perilaku Keputusan Pembelian}

Seperti yang telah disampaikan oleh Levy \& Weitz (dalam Zulfikar, 2008) yang mengungkapkan bahwa bauran retail merupakan kombinasi dari faktor-faktor retail yang digunakan untuk memuaskan kebutuhan pelanggan sehingga dapat mempengaruhi keputusan pembelian. Dimana bauran retail tersebut terdiri atas faktor-faktor barang dagangan (merchandising), harga (price), 
promosi (promotion), rancangan toko dan pajangan produk (store design and display merchandise), lokasi (location), pelayanan (service), dan wiraniaga (personel). Sedangkan keputusan pembelian seperti yang disampaikan oleh Peter \& Olson (2000) adalah proses pengintegrasian yang mengkombinasikan pengetahuan untuk mengevaluasi dua atau lebih perilaku alternatif dan memilih salah satu diantaranya.

Keputusan pembelian merupakan salah satu perilaku konsumen dimana konsumen memutuskan untuk membeli produk dan layanan yang ditawarkan perusahaan yang dipengaruhi oleh berbagai aspek, seperti harga, kualitas produk dan layanan atau lainnya. Penelitian yang dilakukan oleh Rav (2009) mengemukakan bahwa keputusan pembelian konsumen (Customer Purchase Decision) merupakan persepsi konsumen terhadap perusahaan yang dapat dipengaruhi oleh brand, quality, price, products, dan prmotion. Hal yang sama disampaikan oleh Zulfikar (2008) dikemukakan pula bahwa bauran retail berpengaruh pula kepada loyalitas pelanggan pada Toserba X di Bandung. Menurutnya keputusan pembelian pada sebuah toserba dipengaruhi oleh baruan retail yang terdiri atas Merchandising, Price, Location, Promotion, Store Design \& Visual Product, Service, dan Personel.

\section{Kerangka Pemikiran}

Atas dasar hasil kajian literatur yang telah disampaikan di atas maka penelitian ini akan melakukan kajian tentang pengaruh bauran retail terhadap keputusan pembelian konsumen pada suatu departemen store di Jakarta dengan kerangka pemikiran sebagai berikut:

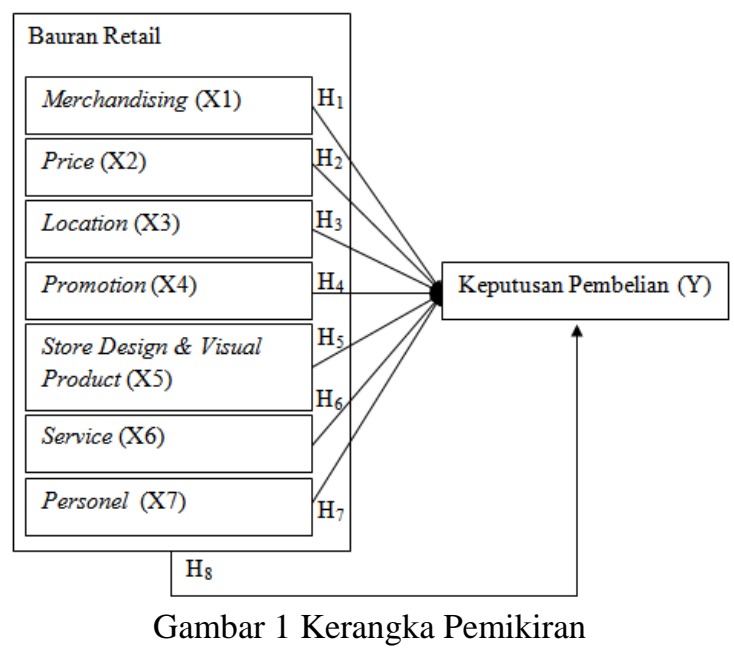

Atas dasar kerangka model penelitian di atas, maka penelitian ini akan menguji hipotesis sebagai berikut: $\mathrm{H}_{1}$ : merchandising berpengaruh terhadap keputusan pembelian; $\mathrm{H}_{2}$ : price berpengaruh berpengaruh terhadap keputusan pembelian; $\mathrm{H}_{3}$ : location berpengaruh berpengaruh terhadap keputusan pembelian; $\mathrm{H}_{4}$ : promotion berpengaruh terhadap keputusan pembelian; $\mathrm{H}_{5}$ : store design \& visual product berpengaruh terhadap keputusan pembelian; $\mathrm{H}_{6}$ : service berpengaruh terhadap keputusan pembelian; $\mathrm{H}_{7}$ : personel berpengaruh terhadap keputusan pembelian; $\mathrm{H}_{8}$ : bauran retail yang terdiri atas Merchandising, Price, Location, Promotion, Store Design \& visual product, service, dan personel secara bersama-sama berpengaruh terhadap keputusan Pembelian.

\section{METODE PENELITIAN}

Untuk menguji hipotesis yang telah disampaikan di atas, penelitian yang digunakan dalam penelitian ini adalah metode kausal dan deskriptif. Menurut Sugiyono (2003) metode kausal merupakan metode yang menjelaskan tentang mencari penyebab atau pengaruh dari variabel dependen 
kepada variabel independen, sedangkan metode deskriptif merupakan penelitian terhadap masalahmasalah berupa fakta-fakta saat ini dari suatu populasi. Tipe penelitian ini umumnya berkaitan dengan opini (individu, kelompok atau organisasi) kejadian atau prosedur.

Penelitian tentang keputusan pembelian konsumen yang didasarkan kepada bauran retail dilakukan dengan menggunakan asosiatif, seperti yang disampaikan pada Tabel 1 di bawah ini.

Tabel 1 Desain Penelitian

\begin{tabular}{|c|c|c|c|c|}
\hline \multirow{2}{*}{$\begin{array}{c}\text { Tujuan } \\
\text { Penelitian }\end{array}$} & \multicolumn{4}{|c|}{ Desain Penelitian } \\
\hline & $\begin{array}{c}\text { Jenis } \\
\text { Penelitian }\end{array}$ & $\begin{array}{c}\text { Metode } \\
\text { Penelitian }\end{array}$ & $\begin{array}{c}\text { Unit } \\
\text { Analisis }\end{array}$ & Time Horizon \\
\hline $\mathrm{T}-1$ & Asosiatif & Survey & Individu \& Konsumen & Cross Sectional \\
\hline $\mathrm{T}-2$ & Asosiatif & Survey & Individu \& Konsumen & Cross Sectional \\
\hline $\mathrm{T}-3$ & Asosiatif & Survey & Individu \& Konsumen & Cross Sectional \\
\hline $\mathrm{T}-4$ & Asosiatif & Survey & Individu \& Konsumen & Cross Sectional \\
\hline $\mathrm{T}-5$ & Asosiatif & Survey & Individu \& Konsumen & Cross Sectional \\
\hline T-6 & Asosiatif & Survey & Individu \& Konsumen & Cross Sectional \\
\hline $\mathrm{T}-7$ & Asosiatif & Survey & Individu \& Konsumen & Cross Sectional \\
\hline $\mathrm{T}-8$ & Asosiatif & Survey & Individu \& Konsumen & Cross Sectional \\
\hline
\end{tabular}

Sumber: Hasil Pengolahan Penulis (2010)

Penelitian ini terdiri atas dua variabel, yaitu bauran retail sebagai variabel independen dan keputusan pembelian konsumen sebagai variabel dependen. Definisi operasional bauran retail adalah penilaian responden atas penerapan bauran retail yang dijalankan oleh Pasaraya. Variabel ini diukur dengan menggunakan indikator-indikator barang dagangan (merchandising), harga (price), promosi (promotion), rancangan toko dan pajangan produk (store design and display merchandise), lokasi (location), pelayanan (service), dan wiraniaga (personel). Definisi operasional pengambilan keputusan pembelian konsumen adalah perilaku konsumen dalam memutuskan memilih Departemen Store $\mathrm{X}$ sebagai tempat tujuan belanja. Variabel ini diukur berdasarkan kondisi keuangan dan pengaruh orang lain. Berikut disampaikan indikator pengukurannya seperti pada Tabel 2 di bawah ini.

Tabel 2 Operasional Variabel

\begin{tabular}{|c|c|c|c|c|c|}
\hline Variabel & Dimensi & Indikator & $\begin{array}{c}\text { Instrumen } \\
\text { Ukuran }\end{array}$ & Skala & $\begin{array}{c}\text { Skala } \\
\text { Ukuran }\end{array}$ \\
\hline \multirow{7}{*}{ Bauran Retail } & merchandising & $\begin{array}{l}\text { Kelengkapan Jenis } \\
\text { Kelengkapan Merek } \\
\text { Keragaman Produk }\end{array}$ & Kuesioner & Ordinal mejadi Interval & Likert \\
\hline & price & $\begin{array}{l}\text { Daya saing Harga } \\
\text { Sesuai dengan Kualitas } \\
\text { Kemudahan Transaksi } \\
\text { Lokasi Strategis }\end{array}$ & Kuesioner & Ordinal mejadi Interval & Likert \\
\hline & Location & $\begin{array}{l}\text { Lahan Parkir } \\
\text { Kenyamanan Lokasi } \\
\text { Gencar Berpromosi }\end{array}$ & Kuesioner & Ordinal mejadi Interval & Likert \\
\hline & promotion & $\begin{array}{l}\text { Diskon Menarik } \\
\text { Keragaman Media }\end{array}$ & Kuesioner & Ordinal mejadi Interval & Likert \\
\hline & $\begin{array}{l}\text { store design and } \\
\text { display } \\
\text { merchandise }\end{array}$ & $\begin{array}{l}\text { Display Menarik } \\
\text { Kemudahan Tata Letak } \\
\text { Penujuk Arah } \\
\text { Keramahan }\end{array}$ & Kuesioner & Ordinal mejadi Interval & Likert \\
\hline & Service & $\begin{array}{l}\text { Pusat Informasi } \\
\text { Responsif } \\
\text { Kerapihan }\end{array}$ & Kuesioner & Ordinal menjadi Interval & Likert \\
\hline & Personel & $\begin{array}{l}\text { Menarik } \\
\text { Kesamaan Pengetahuan }\end{array}$ & Kuesioner & Ordinal menjadi Interval & Likert \\
\hline
\end{tabular}


Tabel 2 Operasional Variabel (lanjutan)

\begin{tabular}{|c|c|c|c|c|c|}
\hline Variabel & Dimensi & Indikator & $\begin{array}{c}\text { Instrumen } \\
\text { Ukuran }\end{array}$ & Skala & $\begin{array}{l}\text { Skala } \\
\text { Ukuran }\end{array}$ \\
\hline \multirow{7}{*}{$\begin{array}{c}\text { Keputusan } \\
\text { Pembelian } \\
\text { (Y) }\end{array}$} & Fasilitas & Fasilitas yang Sesuai & Kuesioner & Ordinal menjadi Interval & Likert \\
\hline & Saran Orang Lain & Saran yang Berguna & Kuesioner & Ordinal menjadi Interval & Likert \\
\hline & Informasi & Kemudahan Informasi & Kuesioner & Ordinal menjadi Interval & Likert \\
\hline & Keunggulan & Keunggulan dari yang lain & Kuesioner & Ordinal menjadi Interval & Likert \\
\hline & Minat & Minat Membeli & Kuesioner & Ordinal menjadi Interval & Likert \\
\hline & Kepuasan & Tingkat Kepuasan & Kuesioner & Ordinal menjadi Interval & Likert \\
\hline & $\begin{array}{l}\text { Perilaku pasca } \\
\text { pembelian }\end{array}$ & $\begin{array}{l}\text { Merekomendasikan ke orang } \\
\text { lain }\end{array}$ & Kuesioner & Ordinal menjadi Interval & Likert \\
\hline
\end{tabular}

Penentuan sampel dalam penelitian ini menggunakan nonprobability sampling. Pertimbangan dari peneliti menggunakan sampel jenis nonprobability karena prosedurnya memenuhi tujuan pengambilan sampel secara memuaskan, alasan lain adalah karena adanya keterbatasan waktu dan biaya (Cooper \& Schindler, 2003).

Adapun teknik nonprobability sampling yang dipakai dalam penelitian ini adalah purposive sampling, yaitu sampel nonprobabilita yang menyesuaikan diri dengan kriteria tertentu (Cooper \& Schindler, 2003) dan memahami tentang objek dalam atribut produk yang diteliti.. Kriteria responden yang menjadi acuan dalam penelitian ini adalah pembeli yang melakukan pembelian di Pasaraya Departemen Store. Penentuan ukuran sampel pada penelitian menggunakan asumsi Hair, Anderson, Tatham \& Block (1995) yang menyatakan bahwa ketika tidak dapat mendapatkan ukuran sampel yang benar diajukan ukuran sampel yang digunakan adalah antara 100-200 sampel. Sehingga pada penelitian ini sampel yang diambil adalah sebesar 100 responden. Penetapan jumlah responden ini didasarkan kepada tidak diketahuinya jumlah pengunjung secara pasti yang melakukan transaksi pembelian.

Metode pengumpulan data disesuaikan berdasarkan jenis data yang diperoleh dalam penelitian terdiri dari atas dua bagian yaitu data primer dan data sekunder. Data Primer, yaitu data yang diperoleh melalui survey secara langsung kepada obyek penelitian. Data ini diperoleh melalui metode penyebaran kuesioner. Instrumen ini merupakan salah satu alat untuk pengumpulan data primer pada penelitian ini. Kuesioner terdiri dari pertanyaan dengan jawaban telah disediakan dengan menggunakan skala Likert. Kuesioner diberikan kepada responden penelitian. Skala Likert yang digunakan dalam penelitian ini meliputi lima jenjang tingkatan seperti yang disampaikan pada tabel di bawah ini.

Tabel 3 Skala Likert

\begin{tabular}{lc}
\hline \multicolumn{1}{c}{ Jenjang Pendapat Responden } & Skor Penilaian \\
\hline Sangat Setuju & 5 \\
Setuju & 4 \\
Netral & 3 \\
Tidak Setuju & 2 \\
Sangat Tidak Setuju & 1 \\
\hline
\end{tabular}

Sementara itu, data sekunder, yaitu data yang diperoleh dari dari berbagia sumber media dan literatur serta data artikel yang terkait dengan topik penelitian dalam bentuk studi kepustakaan.

Alat pengumpul data yaitu instrumen kuesioner akan dilakukan pengujian terlebih dahulu sebelum digunakan atau disebarkan kepada responden. Pengujian instrumen kuesioner ini dimaksudkan agar setiap atribut pernyataan dinyatakan valid dan variabel yang diukur dinyatakan reliabel atau andal, sehingga layak digunakan sebagai alat pemgumpul data penelitian. Pengujian instrumen terdiri atas uji validitas dan uji reliabilitas. 
Pengujian validitas dilakukan untuk memastikan bahwa instrumen yang akan digunakan layak dijadikan alat pengumpul data yang dipahami dan dipersepsikan oleh responden sesuai dengan tujuan penelitian. Pengujian validitas dilakukan dengan menggunakan analisis korelasi Pearson Correlation. Menurut Ghozali (2007) keputusan suatu instrumen dinyatakan valid dengan ketentuan:

$$
\begin{aligned}
& \text { Jika } \mathrm{r}_{\text {hitung }}>\mathrm{r}_{\text {tabel }} \text { maka indikator dikatakan valid. } \\
& \text { Jika } \mathrm{r}_{\text {hitung }}<\mathrm{r}_{\text {tabel }} \text { maka indikator dikatakan tidak valid. }
\end{aligned}
$$

Di mana nilai $r_{\text {tabel }}$ untuk $n=100$ dan $\alpha=0.05$ adalah 0.349 , sehingga seluruh atribut akan dinyatakan valid bila memiliki nilai $r_{\text {hitung }}$ di atas 0.349 . Hasil Pengujian seperti yang disampaikan pada tabel diperlihatkan bahwa keseluruhan indikator dinyatakan valid dan layak dijadikan instrumen penelitian.

Tabel 4 Hasil Pengujian Validitas

\begin{tabular}{cccccccccc}
\hline \multicolumn{3}{c}{ Merchandising } & \multicolumn{9}{c}{$\begin{array}{c}\text { Store design and display } \\
\text { merchandise }\end{array}$} \\
\hline Merch1 & 0.722 & Valid & Store1 & 0.823 & Valid & Perso1 & 0.930 & Valid \\
Merch2 & 0.848 & Valid & Store2 & 0.846 & Valid & Perso2 & 0.963 & Valid \\
Merch2 & 0.707 & Valid & Store3 & 0.832 & Valid & Perso3 & 0.883 & Valid \\
& Price & & & Location & & & & & \\
Price1 & 0.760 & Valid & Loc1 & 0.764 & Valid & & Purchase Decesion & \\
Price2 & 0.785 & Valid & Loc2 & 0.914 & Valid & Purch1 & 0.760836 & Valid \\
Price3 & 0.545 & Valid & Loc3 & 0.929 & Valid & Purch2 & 0.96743 & Valid \\
& Promotion & & & Service & & Purch3 & 0.963733 & Valid \\
Prom1 & 0.925 & Valid & Serv1 & 0.795 & Valid & Purch4 & 0.941251 & Valid \\
Prom2 & 0.844 & Valid & Serv2 & 0.805 & Valid & Purch5 & 0.884638 & Valid \\
Prom3 & 0.876 & Valid & Serv3 & 0.844 & Valid & Purch6 & 0.946092 & Valid \\
\hline
\end{tabular}

Sumber: Hasil Penelitian (2010)

Pengujian reliabilitas digunakan untuk mengetahui konsistensi internal diantara item-item pernyataan dalam suatu instrumen penelitian. Mengingat alat pengukur yang digunakan untuk mengukur variabel-variabel dalam penelitian ini adalah kuesioner yang terdiri dari beberapa pertanyaan, maka perlu diuji reliabilitas dari setiap variabel yang digunakan dengan melihat Chronbach's coefficient alpha untuk melihat koefisien reliabilitas per kelompok. (Ghozali, 2007).

Pengambilan keputusan koefisien chronbach alpha adalah Chronbach's coefficient alpha kurang dari 0.60 poor acceptable, antara 0.60-0.70 cukup dapat diterima (acceptable), sedangkan jika Chronbach's coefficient alpha lebih besar 0.80 adalah good acceptable (Sekaran, 2000). Sehingga atas dasar hal tersebut, maka dasar keputusan realibilitas suatu variabel adalah:

Cronbach's Alpha > 0.60, maka Cronbach's coefficient alpha dapat diterima

Cronbach's Alpha < 0.60, maka Cronbach's coefficient alpha tidak dapat diterima (poor acceptable).

Hasil pengujian reliabilitas dengan ketentuan tersebut di atas didapatkan bahwa kedua variabel penelitian dinyatakan reliabel karena memiliki nilai Cronbach's Alpha di atas 0.60 sehingga layak dijadikan instrumen penelitian. Hal ini seperti yang ditunjukan pada tabel berikut ini. 
Tabel 5 Hasil Pengujian Reliabilitas

\begin{tabular}{lcc}
\hline \multicolumn{1}{c}{ Variabel } & Cronbach's Alpha & Status \\
\hline Merchandising & 0.637 & Reliabel \\
Price & 0.658 & Reliabel \\
Promotion & 0.857 & Reliabel \\
Store design and display merchandise & 0.776 & Reliabel \\
Location & 0.840 & Reliabel \\
Service & 0.746 & Reliabel \\
Personnel & 0.917 & Reliabel \\
Purchase Decesion & 0.964 & Reliabel \\
\hline
\end{tabular}

Sumber: Hasil Penelitian (2010)

Metoda analisis yang digunakan adalah metoda analisis regresi berganda. Metoda ini digunakan untuk menguji seberapa besar pengaruh variabel independen yang lebih dari satu variabel secara lansung kepada tidak langsung kepada variabel dependen. Metoda analisis regresi mensyaratkan pada data yang digunakan haruslah data internal.

Skala Likert yang disampaikan pada tabel di atas merupakan skala ordinal, sedangkan pada penelitian dengan menggunakan metoda analisis regresi maka skala yang digunakan adalah skala internal. sehingga untuk merubah antara skala ordinal menjadi skala interval, maka digunakan Metode Succesive Interval (MSI). Metode ini digunakan untuk melakukan transformasi data ordinal menjadi data interval (Hays, 1976). Hal ini karena jawaban responden yang diukur dengan menggunakan skala Likert (Lykert scale) diadakan scoring yakni pemberian nilai numerikal 1, 2, 3, 4 dan 5, setiap skor yang diperoleh akan memiliki tingkat pengukuran ordinal. Pada metode analisi regresi tidak mengenal data ordinal, sehingga data ordinal tersebut ditransformasi menjadi data interval dengan menggunakan metoda MSI. Transformasi data ini menggunakan aplikasi MSI.

\section{HASIL DAN PEMBAHASAN}

\section{Profil Responden}

Penelitian ini melibatkan 100 orang pelanggan pada Departemen Store X, di aman sebagian besar responden berjenis kelamin perempuan dengan proporsi mencapai 59 persen, sedangkan lakilaki hanya 41 persen. Sebagian besar responden berusia antara 30-45 tahun dengan proporsi 43 persen, di bawah 30 tahun sebanyak 38 persen, dan di atas 45 tahun sebanyak 19 persen. Tingkat pendidikan sebagian besar Diploma sebanyak 37 persen, Sarjana 32 persen, SLTA 22 persen, dan Pascasarjana 9 persen. Perilaku frekwensi berbelanja dalam sebulan sebanyak dua kali dengan proporsi 32 persen, empat kali dalam sebulan sebanyak 29 persen, satu kali sebulan sebanyak 27 persen, dan tiga kali sebulan sebanyak 12 persen. Sedangkan bila dilihat lamanya telah menjadi pelanggan setia di Departemen Store X, maka dapat dilihat bahwa sebagian besar responden telah menjadi pelanggan belum mencapai satu tahun dengan proporsi mencapai 27 persen, namun terdapat pula pelanggan yang telah menjadi pelanggan lebih dari empat tahun mencapai 14 persen. Perincian atas proporsi profil responden tersebut disampaikan pada Tabel 4.

Atas dasar hasil informasi profil responden tersebut maka dapat dilihat bahwa Departemen Store X lebih banyak diminati oleh kaum perempuan dengan rentang usia antara 30-45 tahun, dan berpendidikan pada jenjan Diploma. Selain itu perilaku frekwensi pembelian yang sering dilakukan dalam sebulan adalah dua kali, dan sebagian besar dari mereka merupakan pelanggan-pelanggan baru yang telah menjadi pelanggan setia masih di bawah satu tahun. 
Tabel 6 Profil Responden

\begin{tabular}{lc}
\hline \multicolumn{1}{c}{ Variabel } & Persentase \\
\hline Jenis Kelamin & \\
Laki & 41.00 \\
Perempuan & 59.00 \\
Usia & \\
$<30$ & 38.00 \\
$30-45$ & 43.00 \\
$>45$ & 19.00 \\
Pendidikan & \\
SLTA & 22.00 \\
Diploma & 37.00 \\
Sarjana & 32.00 \\
Pascasarjana & 9.00 \\
Frekwensi Berbelanja dalam satu bulan di Departemen Store X & \\
Satu kali & 27.00 \\
Dua kali & 32.00 \\
Tiga kali & 12.00 \\
Empat kali & 29.00 \\
Lamanya telah menjadi pelanggan di Departemen Store X & \\
$<1$ Tahun & 27.00 \\
1-2 Tahun & 9.00 \\
2-3 Tahun & 9.00 \\
3-4 Tahun & 9.00 \\
$>4$ Tahun & 14.00 \\
\hline
\end{tabular}

Sumber: Hasil Penelitian

\section{Analisis Deskriptif}

Untuk melihat penilaian responden terhadap ketujuh aspek dalam Bauran Retail, maka pada Tabel 5 di bawah ini. Pada tabel tersebut terlihat bahwa dari ketujuh aspek Bauran Retail, aspek Price merupakan aspek yang mendapatkan penilaian tertinggi yaitu mencapai 4.12 (pada kisaran skala 4.00). Nilai ini memberikan indikasi bahwa sebagian besar responden menyatakan setuju Departemen Store X memiliki keunggulan dalam hal Store Design \& Visual Product. Namun aspek Merchandising merupakan aspek dari Bauran Retail yang mendapatkan penilaian kurang baik, artinya Departemen Store $\mathrm{X}$ belum memenuhi harapan atas keragaman produk yang diminati responden.

Tabel 7 Deskriptif Variabel

\begin{tabular}{lc}
\hline \multicolumn{1}{c}{ Variabel } & Nilai Rata-rata Tanggapan \\
\hline Bauran Retail & \\
Merchandising (X1) & 3.49 \\
Price (X2) & 3.92 \\
Location (X3) & 3.64 \\
Promotion (X4) & 3.85 \\
Store Design \& Visual Product (X5) & 4.12 \\
Service (X6) & 3.95 \\
Personel (X7) & 4.04 \\
Keputusan Pembelian Konsumen & 3.70 \\
\hline
\end{tabular}

Sumber: Hasil Penelitian

\section{Pengaruh Baruan Retail terhadap Keputusan Pembelian Konsumen}

Sebelum menganalisis pengaruh dari Bauran Retail terhadap Keputusan Pembelian Konsumen, maka dapat Tabel 6 diperlihatkan keterkaitan hubungan antara kedua variabel yang diuji. Seperti yang disampaikan pada tabel tersebut, diperlihatkan bahwa kedua variabel penelitian memberikan hubungan yang erat, hal ini diperlihatkan dengan besarnya nilai koefisien korelasi sebesar 0.777. Dimana nilai tersebut mendekati satu, artinya kedua variabel penelitian memiliki hubungan yang erat. Sedangkan koefisien determinasi menjelasikan seberapa besar variabel independen dapat 
menjelaskan variabel dependen. Pada tabel diperlihatkan nilai sebesar 0.603, artinya variabel Bauran Retail dapat menjelaskan variabel Keputusan Pembelian Konsumen mencapai 60.3 persen. Atau dengan makna lain bahwa Bauran Retail mampu memberikan kontribusi mencapai 60.3 persen bagi Keputusan Pembelian Konsumen.

Tabel 8 Korelasi dan Determinasi

Model Summary

\begin{tabular}{|l|r|r|r|r|}
\hline Model & R & R Square & $\begin{array}{c}\text { Adjusted } \\
\text { R Square }\end{array}$ & $\begin{array}{r}\text { Std. Error of } \\
\text { the Estimate }\end{array}$ \\
\hline 1 & $.777^{\mathrm{a}}$ & .603 & .573 & 3.36114 \\
\hline
\end{tabular}

a. Predictors: (Constant), Prs, Mch, Loc, Prc, StD, Pro, Srv

Untuk mengetahui apakah ketujuh aspek Bauran Retail secara bersama-sama berpengaruh terhadap Keputusan Pembelian Konsumen, maka dapat diperlihatkan pada hasil analisis yang disampaikan pada Tabel 7. Pada tabel tersebut diperlihatkan hasil nilai signifikansi sebesar 0.000 , nilai tersebut lebih kecil dari 0.05 atau 5\%, yaitu ambang batas tingkat kesalahan yang ditetapkan oleh peneliti. Sehingga atas dasar hasil tersebut dapat disampaikan bahwa secara keseluruhan, ketujuh aspek pada Bauran Retail, secara bersama-sama telah memberikan pengaruh terhadap Keputusan Pembelian Konsumen.

Tabel 9 ANOVA

ANOVA

\begin{tabular}{|ll|l|r|r|r|r|}
\hline Model & & $\begin{array}{l}\text { Sum of } \\
\text { Squares }\end{array}$ & df & Mean Square & F & Sig. \\
\hline 1 & Regression & 1580.985 & 7 & 225.855 & 19.992 & $.000^{\mathrm{a}}$ \\
& Residual & 1039.348 & 92 & 11.297 & & \\
& Total & 2620.333 & 99 & & & \\
\hline
\end{tabular}

a. Predictors: (Constant), Prs, Mch, Loc, Prc, StD, Pro, Srv

b. Dependent Variable: $C D$

Selanjutnya setelah diketahui bahwa keseluruhan aspek dari Bauran Retail telah memberikan pengaruh secara signfikan terhadap Keputusan Pembelian Konsumen, maka perluanya diketahaui aspek-aspek mana dari ketujuh Bauran Retail yang berpengaruh secara signifikan terhadap Keputusan Pembelian Konsumen. Itu itu dapat dilihat pada hasil pada Tabel 10 di bawah ini. Dari ketujuh aspek tersebut, hanya dua aspek saja yang memberikan pengaruh secara signifikan terhadap Keputusan Pembelian Konsumen, yaitu Price dan People. Hal ini terjadi karena kedua aspek tersebut masingmasing memiliki nilai signifikansi di bawah 0.05 atau 5\%, sedangkan kelima aspek lainnya berada di atas nilai ambang batas signifikansi tersebut.

Tabel 10 Koefisien Regresi

Coefficients $^{\mathbf{a}}$

\begin{tabular}{|ll|r|r|r|r|r|}
\hline \multirow{2}{*}{ Model } & \multicolumn{2}{|c|}{$\begin{array}{c}\text { Unstandardized } \\
\text { Coefficients }\end{array}$} & $\begin{array}{c}\text { Standardized } \\
\text { Coefficients }\end{array}$ & \\
\cline { 2 - 4 } & & \multicolumn{1}{|c|}{$\mathrm{B}$} & Std. Error & \multicolumn{1}{c|}{ Beta } & \multicolumn{1}{c|}{$\mathrm{t}$} & \multicolumn{1}{c|}{ Sig. } \\
\hline 1 & (Constant) & 2.274 & 1.950 & & 1.166 & .247 \\
& Mch & -.246 & .182 & -.106 & -1.353 & .179 \\
& Prc & .927 & .223 & .344 & 4.159 & .000 \\
& Loc & .229 & .192 & .104 & 1.195 & .235 \\
& Pro & .064 & .225 & .029 & .286 & .776 \\
& StD & .222 & .219 & .097 & 1.015 & .313 \\
& Srv & -.078 & .235 & -.035 & -.331 & .742 \\
& Prs & 1.077 & .227 & .480 & 4.736 & .000 \\
\hline
\end{tabular}

a. Dependent Variable: CD 
Atas dasar hasil yang disampaikan pada Tabel 8 di atas, maka dapat disampaikan persamaan regresi sebagai berikut:

$$
\mathrm{Y}_{\mathrm{CD}}=2.274+0.927 \mathrm{X}_{\mathrm{PrC}}+1.077 \mathrm{X}_{\mathrm{Prs}}
$$

Seperti yang disampaikan pada persamaan regresi di atas, maka terlihat bahwa aspek Personel (Prs) merupakan aspek dengan nilai koefisien tertinggi dibandingkan dengan aspek Price (Prc) atau dengan kelima aspek Bauran Retail lainnya. Dengan demikian, dapat ditetapkan bahwa aspek Personel merupakan aspek dari Bauran Retail yang memiliki pengaruh paling dominan terhadap Keputusan Pembelian Konsumen pada departemen store tersebut.

\section{Uji Hipotesis}

Hasil pengujian hipotesis yang telah didapat berdasarkan hasil pengolahan data melalui aplikasi SPSS. Dari delapan hipotesis yang diujikan, tujuh hipotesis dijawab dengan menggunakan Tabel 10, yaitu hipotesis pertama hingga ketujuh, sedangkan satu hipotesis yaitu hipotesis kedelapan dijawab dengan menggunakan Tabel 9. Pada Tabel 5 memperlihatkan bahwa dari tujuh hipotesis yang diuji, hanya hipotesi kedua dan ketujuh yang menyatakan menolak pernyataan Ho, karena nilai Sig menunjukan nilai di bawah 0.05 atau 5\%. Artinya aspek Price dan Personel merupakan dua aspek yang secara signifikan berpengaruh terhadap keputusan pembelian konsumen. Sedangkan lima aspek Bauran Retail lainnya yaitu merchandise, location, promotion, store design \& visual product, dan service tidak memberikan pengaruh secara signifikan terhadap Bauran Retail.

Demikian halnya pada Tabel 9, dihasilkan bahwa secara keseluruhan ketujuh aspek dalam Bauran Retail berpengaruh secara signifikan terhadap Keputusan Pembelian Konsumen, hal ini terlihat pada hasil ANOVA dimana nilai signifikansi yang dihasilkan adalah sebesar 0.000. Nilai signifikansi ini lebih kecil dari 5\% atau 0.05, yaitu batas kesalahan yang ditetapkan oleh peneliti. Dengan demikian hasil penelitian ini telah membuktikan atas hasil yang telah didapat oleh peneliti sebelumnya yaitu Zulfikar (2008). Secara konsep telah disampaikan pula bahwa terdapat pengaruh antara baruan retail terhadap keputusan pembelian. Sedangkan penelitian yang dilakukan Zulfikar (2008), Bauran Retail juga dapat memberikan pengaruh kepada loyalitas pelanggan pada Toserba X di Bandung.

\section{PENUTUP}

Berdasarkan hasil analisis yang telah disampaikan di atas, diperlihatkan bahwa dari tujuh aspek Bauran Retail yang diujikan, hanya terdapat dua aspek yang dapat memberikan pengaruh secara siginfikan terhadap Keputusan Pembelian Konsumen pada departeen store, yaitu aspek price dan personel, sedangkan lima aspek lainnya tidak memberikan pengaruh secara signifikan yaitu merchandise, location, promotion, store design \& visual product, dan Service. Namun secara keseluruhan, dengan menggunakan uji ANOVA didapatkan hasil bahwa secara bersama-sama ketujuh aspek Bauran Retail secara signifikan berpengaruh terhadap Keputusan Pembelian Konsumen. Sebagai saran yang dapat diberikan kepada sebuah departemen store di mana penelitian ini dilakukan yaitu dengan melihat hasil penilaian pelanggan. Seperti yang disampaikan pada Tabel 7 terlihat bahwa Merchandising merupakan aspek dari bauran retail yang memiliki nilai terendah dibandingkan dengan enam aspek lainnya, dan bila diteliti lebih mendalam lagi maka terlihat bahwa atribut kelengkapan produk dengan merek-merek terkenal memiliki nilai terendah. Hal ini memberikan indikasi bahwa departemen store tersebut sebagai pusat perbelanjaan dengan segmen menengah ke atas masih memiliki keterbatasan dalam hal kelengkapan produk pada merek-merek terkenal. Sehingga dapat disarankan gara dapat melengkapi produk-produk tersebut sesuai dengan harapan pelanggan. Selanjutnya aspek bauran retail yang telah dijalankan dengan baik adalah Store Design \& Visual Product terutama pada atribut tata letak produk sehingga memudahan konsumen dalam mencari 
produk yang diinginkan. Atribut tersebut telah dijalankan dengan baik sehingga perusahaan perlu mempertahankan tata letak produk tersebut sehingga dapat memberikan kemudahan pelanggan dalam mendapatkan produk-produk yang diinginkannya.

\section{DAFTAR PUSTAKA}

Assael, H. (2001). Consumer behavior and marketing action. Singapura: Thomson Learning.

Cooper, D. R., \& Schindler, P. S. (2006). Metode riset bisnis. Jakarta: Penerbit Media Global Edukasi.

Davidson, W. R., Sweeney, D. J., \& Stampfl, R. W. (1988). Retailing Management. New York: John Wiley \& Sons.

Ghozali, I. (2007). Aplikasi analisis multivariate dengan program SPSS. Semarang: Badan Penerbit Universitas Diponegoro.

Hair, J. F., Anderson, R. F., Tatham, R. L., \& Block, W. C. (1995). Multivariate data analysis (5th ed.). New Jersey: Prentice-Hall International.

Hays, W. L, (1976). Quantification in psychology. New Delhi: Prentice Hall.

Khoiri, I. (2011, 9 Januari). Mal dan imajinasi gaya hidup. Kompas.

Kotler, P., \& Armstrong, G. (1994). Principle of marketing (6th ed.). New Jersey: Prentice-Hall.

Mangkunegara, A. P. (1988). Perilaku konsumen. Bandung: Eresco.

Peter, P. J., \& Olson, J. C. (2000). Perilaku konsumen dan strategi pemasaran. Jakarta: Erlangga.

Rav, S. (2009). Building a model for purchase decision of laptops and price-performance analysis of major players. The IUP Journal of Management Research, Vol. 8, No.1.

Schiffman, L. G., \& Kanuk, L. L. (2000) Consumer behavior (7th ed.). Upper Saddle River, New Jersey: Prentice Hall.

Sekaran, U. (2003). Research methods for business (4th ed.). New York: John Wiley \& Sons.

Sugiyono. (2003). Statistik untuk penelitian. Bandung: Alfabeta.

Sumarwan, U. (2004). Perilaku Konsumen. Jakarta: Ghalia Indonesia.

Zulfikar, R. (2008). Pengaruh bauran retail terhadap loyalitas konsumen pada Toserba X di kota Bandung. Jakarta: Universitas Komputer Indonesia. 